\title{
Kütahya İli Üretici Depolarından Alınan Buğday Örneklerinde Bulunan Zararlı Böcek Türleri ve Doğal Düşmanları
}

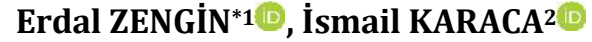 \\ ${ }^{1}$ Tarım ve Orman İl Müdürlüğ̈̈, 64100, Uşak \\ ${ }^{2}$ Isparta Uygulamalı Bilimler Üniversitesi, Ziraat Fakültesi, Bitki Koruma Bölümü, 32100, Isparta
}

(Alınış / Received: 03.12.2019, Kabul / Accepted: 16.01.2020, Online Yayınlanma / Published Online: 20.04.2020)

\begin{abstract}
Anahtar Kelimeler Depolanmış buğday, Böcek yoğunluğu, Zarar oranı, Kütahya
\end{abstract}

Özet: Bu çalışma 2017 yllında Kütahya ili üretici depolarında bulunan buğdaylardaki zararlı ve yararlı böcek türleri ve bu türlerin yoğunluklarının tespiti ile depolarda sebep oldukları zarar oranlarının belirlenmesi amacı ile yapılmıștır. 24 farklı köyden alınan toplam 41 örneğin incelenmesi sonucunda, Sitophilus granarius (L.), Oryzaphilus surinamensis (L.), Tribolium castaneum (Herbst), Tenebroides mauritanicus (L.), Tenebrio molitor (L.), Anthrenus scrophulariae var. albidus (Reitter), Dienerella sp. (Reitter), Stegobium paniceum (L.), Plodia interpunctella (Hübner) ve Ephestia cautella (Walker) olmak üzere toplam 10 böcek türü zararlı olarak tespit edilmiştir. Ayrıca Lariophagus distinguendus (Förster), Anisopteromalus calandrae (Howard) ve Bracon hebetor (Say) türleri doğal düşman olarak bulunmuștur. Zararlı türlerden S. granarius ve 0 . surinamensis sirasıyla örneklerdeki yoğunluk (\%52.6-\%40.2) ve bulaşıklık (\%56.1-\%46.3) bakımından en fazla karşılaşılan türler olmuştur. Örneklerde zarar görmüş tane ortalaması en yüksek \%10 olarak tespit edilmiş olup, il ortalaması \%1.39 bulunmuştur. Tespit edilen 13 farklı böcek türünden, Anthrenus scrophulariae var. albidus'un Türkiye'de ilk kez buğday depolarındaki varlığı bu çalışmayla ortaya konulmuştur.

\section{Harmful Insects and Their Natural Enemies on Wheat Samples taken from Producer Warehouses in Kütahya Province}

\section{Keywords}

Stored wheat, Insect density, Damage ratio, Kütahya

\begin{abstract}
This study was carried out to determine harmful and beneficial insect species and their densities in wheat that is in producer warehouses of Kütahya province in 2017. In a total of 41 samples taken from 24 villages, it was detected 10 harmful insects species, namely Sitophilus granarius (L.), Oryzaphilus surinamensis (L.), Tribolium castaneum (Herbst), Tenebroides mauritanicus (L.), Tenebrio molitor (L.), Anthrenus scrophulariae var. albidus (Reitter), Dienerella sp. (Reitter), Stegobium paniceum (L.), Plodia interpunctella (Hübner) and Ephestia cautella (Walker). Furthermore, Lariophagus distinguendus (Förster), Anisopteromalus calandrae (Howard) and Bracon hebetor (Say) were found as natural enemy. The most common species in the samples in terms of density and infestation were S. granarius $(52.6 \%-56.1 \%)$ and 0 . surinamensis (40.2\%-46.3\%), respectively. Although the highest damaged kernel ratio in the samples was calculated to be $10 \%$, provincial avarage was $1.39 \%$. As a result of this study, 13 different insect pest species were detected and Anthrenus scrophulariae var. albidus was firstly detected on stored wheat in Turkey.
\end{abstract}

\section{Giriş}

Buğday temel besin maddemiz olmasından dolayı diğer tarımsal ürünlere nazaran ayrı bir öneme sahiptir. Ayrıca son yıllarda yenilenebilir enerji için hammadde olarak kullanılmasının yanında saman, kepek, razmol gibi yan ürünlerinin yem sanayisinde uzun yıllardır kullanılıyor olması bu önemi daha da artırmıştır. 2017 verilerine göre ülkemizin yaklaşık
23 milyon hektarlık tarım alanının 7.6 milyon hektarlık kısmında (\%33) buğday üretimi yapılmaktadır. Kütahya ilinde ise bu oran toplam ekilebilir alanının (320 bin hektar) \%44'üne (140 bin hektar) karşllık gelmektedir [1]. Artan nüfusun talebinin karşılanması, iklim değişikliklerinden dolayı yaşanan olumsuzluklar, buğdaydan elde edilen ürünlerin ihracatında gerçekleşen artış gibi nedenlerden dolayı buğday üretiminde, gerek tarlada 
gerekse depolamada yaşanan kayıpların en aza indirgenmesi zorunlu hale gelmiştir. Dünya genelinde, depolanmış tahıllarda meydana gelen kayıp yaklaşık \%10 olarak kabul edilmiş olup bu kaybın \%5’lik kısmının böcek zararından dolayı kaynaklandığı tahmin edilmektedir [2]. Türkiye'de ise böcekler tarafından depolarda sebep olunan kaybın \%10 seviyelerinde olduğu belirlenmiştir [3].

32 takım içinde sınıflandırılan böceklerin sadece 3 takımı (Coleoptera, Lepidoptera, Psocoptera) depolanmış ürünlerde zarar yapan böcekleri içerir [4]. Herhangi bir nedenle zarara uğramamış, sağlam buğday tanesi ile beslenerek zarar yapabilen böcek türleri primer zararlı olarak adlandırılmaktadır. Bu zararlılardan depolanmış buğdaylarda sıcça karşılaşılanlar, Sitophilus granarius (L.) (Coleoptera: Curculionidae), Rhyzopertha dominica (Fabricius) (Coleoptera: Bostrichidae), Sitotroga cerealella (Olivier) (Lepidoptera: Gelechiidae) ve Trogoderma granarium (Everts) (Coleoptera: Dermestidae)'dur [4]. Diğer zararlı türlerin hepsi primer zararlılar ya da farklı etmenler tarafından kırılmış, çatlamış veya yenmiş taneler üzerinde ve bunların tozlarıyla beslenirler. $\mathrm{Bu}$ tür zararlılara da sekonder zararlı olarak tanımlanmaktadır. Başka bir depo zararlısı türü ise doğrudan buğday tanesi üzerinde beslenmeyip metabolik aktivitesi yüzünden ortamın sıcaklığını ve nemini arttırarak fungal gelişimi teşvik etmekte ve depolarda bulunan ürünün bozulmasına neden olmaktadır. $\mathrm{Bu}$ türlerin en önemlileri Ahasverus advena (Waltl) (Coleoptera: Silvanidae), Cryptolestes ferrugineus (Stephens) (Coleoptera: Laemophloeidae) ve Liposcelis spp. (Motschulsky) (Psocoptera: Liposcelididae) türleridir [3-5].

$\mathrm{Bu}$ çalışmayla Kütahya ilinde üretici depolarında muhafaza edilen buğdaylarda zarar yapan böcek türleri, bunların yoğunlukları ve depolardaki zarar oranları ile faydalı türlerin durumu ortaya çıkarılmaya çalışılmıştır.

\section{Materyal ve Metot}

Kütahya ili ve ilçelerinde bulunan üretici depolarındaki buğdaylarda zarar meydana getiren böceklerin ve onların doğal düşmanlarının tespit edilmesi amacıyla, 2017 Haziran-Eylül ayları arasında Altıntaş, Emet, Gediz, Hisarcık, Simav ve Şaphane ilçelerinde bulunan 23 köyden toplam 41 adet örnek alınmıştır. Çalışmanın yapıldığı köylerde üreticiler tarafından buğday depolama işlemi kısa süreli yapıldığından, örnekler hasat tarihini kapsayacak şekilde 4 aylık dönem içerisinde alınmıştır.

Örnekler, betonarme veya ahşap özellikteki depolarda yığın ya da çuvallanmış olarak bulunan buğdayların dört farklı noktasından ya da dört çuvaldan, yüzeyden ve yaklaşık $50 \mathrm{~cm}$ derinlikten olmak üzere $2 \mathrm{~kg}$ olacak şekilde elle alınmıştır. Her bir örnekten 66 cl'lik kavanozlara alt örnekler alınarak kavanozların ağızları tül ile kapatılmış ve üzerleri örneklerin alındığı yer ve tarih bilgisi bulunan etiketlerle etiketlenmiştir. Kavanozlar, buğday tanelerinin içerisinde olabilecek böcek türlerinin çıkışının sağlanması için 2 ay süreyle oda sıcaklığında muhafaza edilmiştir. İki ay sonunda örnekler $2 \mathrm{~mm}$ göz açıklığına sahip metal elekle elenmiş ve her bir örnek içinde bulunan böcek türleri ayıklanarak teşhis için hazırlanmıştır. Örneklerde tespit edilen larvalar plastik kaplara alınarak ergin hale gelinceye kadar oda sıcaklığında bekletilmiş ve sonrasında teşhisleri yapılmıştır.

Alınan buğday örneklerinden elde edilen her bir türün yoğunluk oranı, örnekteki türün birey sayısının aynı örnekteki toplam böcek sayısına oranlanmasıyla bulunmuştur. Türün bulunduğu örnek sayısının toplam örnek sayısına oranı ise o türün bulaşıklık yüzdesini vermiştir. Ayrıca her örnekten rastgele 300 adet buğday tanesi alınarak 100'erli üç gruba ayrılmıştır. Buğday taneleri tek tek kontrol edilerek böcek zararı olanlar sayılmış ve üç grubun ortalaması alınarak o örneğe ait zarar oranı tespit edilmiştir. Kırık ve parçalanmış tanelerin böcek zararından dolayı olup olmadığı tespit edilemeyeceğinden sayıma dahil edilmemiş, sadece üzerinde yuvarlak muntazam çıkış deliklerine sahip taneler sayılmıştır. Zarar görmüș tane sayılarının ilçeler arasındaki karşılaştırılması SPSS 16.0 programı ile tek yönlü (ANOVA) varyans analizi uygulanarak yapılmış olup, ortalamalar arasında fark belirlenen grupların karşılaştırılması ise 0.05 düzeyinde Tukey testi ile yapılmıştır.

Zararlı türlerin teşhisleri Rees [5] ve Canadian Grain Commission [6] göre yapılmıș olup, faydalı türler ise Prof.Dr. Mikdat DOĞANLAR (Biyolojik Mücadele Araștırma Enstitüsü, Adana) ve Prof.Dr. Ahmet BEYARSLAN (Bitlis Eren Üniversitesi, Fen Edebiyat Fakültesi, Biyoloji Bölümü, Bitlis) tarafından tanılanmıştır. Ayrıca dermestid türü Prof. Dr. Jiří HAVA (Czech University of Life Sciences, Faculty of Forestry and Wood Sciences, Czech Republic) tarafından teşhis edilmiştir.

\section{Bulgular ve Tartışma}

Kütahya ili ve ilçelerinden toplanan 41 örnekte 13 böcek türü tespit edilmiştir. Bu türlerin 8 tanesi Coleoptera takımına, 2 tanesi Lepidoptera takımına ve 3 tanesi de Hymenoptera takımına ait türlerdir. Takımların tespit edilme oranları Şekil 1'de verilmiştir.

Coleoptera takımının Curculionidae familyasına ait Sitophilus granarius (Buğday biti), Silvanidae familyasına ait Oryzaphilus surinamensis (Testereli böcek), Tenebrionidae familyasına ait Tribolium castaneum (Herbst) (Un biti), Tenebroides mauritanicus (L.) (Ekin kara böceği) ve Tenebrio molitor (L.) (Un kurdu), Dermestidae familyasina ait Anthrenus scrophulariae var. albidus (Reitter), Latridiidae familyasına ait Dienerella sp. (Reitter) ve 
Anobiidae familyasına ait Stegobium paniceum (L.) türleri tespit edilmiştir. Lepidoptera takımında tespit edilen iki tür Pyralidae familyasına ait olan Plodia interpunctella (Hübner) (Kuru meyve güvesi) ve Ephestia cautella (Walker) (Kuru incir kurdu) olmuştur. Hymenoptera takımından faydalı tür olarak belirlenen Lariophagus distinguendus (Förster) ve Anisopteromalus calandrae (Howard)'nin Pteromalidae familyasına, Bracon hebetor (Say)'un ise Braconidae familyasına ait olduğu görülmüştür.

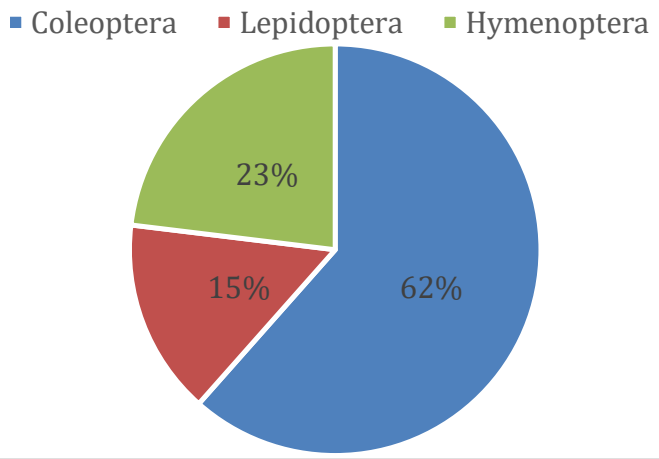

Şekil 1. Kütahya ilinde depolanan buğday örneklerinde tespit edilen böcek türlerinin takım düzeyinde bulunuş oranları (\%)

İncelenen örneklerde 3 takım, 9 familya ve 13 türe ait toplam 2447 adet böcek bulunmuş olup bir örneğe düşen ortalama böcek sayısı 59.7 olarak tespit edilmiştir. Bulunan 13 türün sadece 1 tanesinin primer zararlı (S. granarius) olduğu, 9 tanesinin sekonder zararlı ve 3 tanesinin de depolanmış buğdaylarda zarar yapan bazı türler üzerinde ektoparazitoit olarak beslenen faydalı tür olduğu anlaşılmıştır. Bağcı vd. [7] Ankara ili hububat depolarında yaptıkları çalışmada, Coleoptera ve Psocoptera takımlarına ait toplam 9 türün varlığını tespit etmişler ancak herhangi bir faydalı türün varlığına rastlamamışlardır. Benzer şekilde Coşkuncu [8] Bursa ili un fabrikalarında surveyler gerçekleştirmiş ve sonuç olarak sadece Coleoptera ve Lepidoptera takımlarına ait primer ve sekonder zararlı türlerin varlıklarını tespit etmişlerdir.

Çalışma süresince alınan örneklerde tespit edilen türlerden yoğunluk oranı en fazla olan üç tür; S. granarius (\%52.6), O. surinamensis (\%40.2) ve L. distinguendus (\%3.9) olmuştur (Şekil 2). Tespit edilen faydalı türlerden olan L. distinguendus, alınan 9 örnekte toplam 95 adet, $A$. calandrae, alınan 5 örnekte toplam 41 adet, B. hebetor ise alınan 2 örnekte toplam 5 adet olarak bulunmuştur. B. hebetor'un konukçusu olan $P$. interpunctella'nın toplam 4örnekte 12 adet ve E. cautella'nın da 2 örnekte toplam 5 adet bulunması, bu doğal düşman türün diğer doğal düşmanlara oranla örneklerde daha az tespit edilmesine neden olmuştur. L. distinguendus hem yoğunluk oranı bakımından hem de örneklerdeki bulaşıklık durumu bakımından faydalı türler arasında ilk sırada yer almıștır. Örneklerde bulunan toplam 2447 adet böceğin \%5.8 (141 adet)'ini faydalı türler oluşturmuştur. Bu çalışmadan farklı olarak Güneydoğu Anadolu Bölgesinde Özar vd. [9] tarafından yapılan çalışmada faydalı tür olarak Scenopinus spp. (Diptera: Scenopinidae)'nin hububat depolarında tespit edildiği bildirilmiștir. Her ne kadar bu çalışmada tespit edilen $A$. calandrae ve L. distinguendus'un Türkiye'deki varlığı Öncüer [10] ve Soydanbay-Tunçyürek [11]'de belirtilse de, son yıllarda depolanmış ürünler üzerinde yapılan sürvey çalışmalarının hiçbirinde bu türlerin tespiti yapılamamıştır.

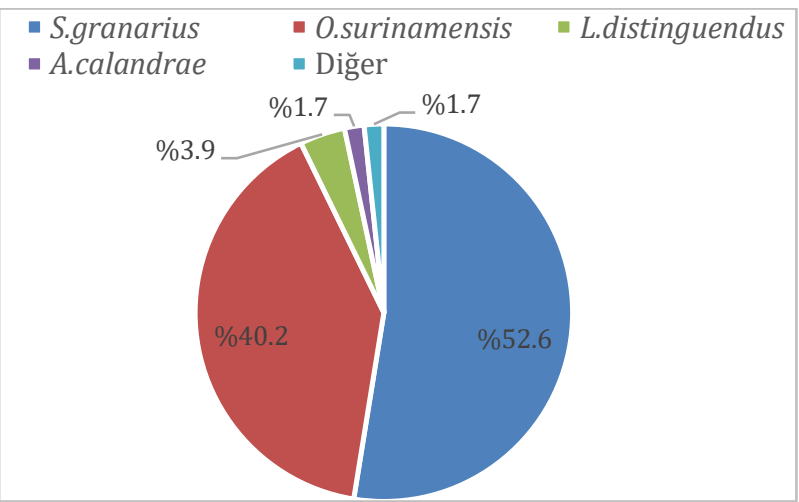

Şekil 2. Kütahya ilinde depolanmış buğdayda tespit edilen türlerin yoğunluk oranları (\%)

Toplanan örneklerin 23 (\%56.1)'ünde S. granarius türüne rastlanmış olup, bu tür örneklerdeki bulaşıklık oranı en yüksek tür olmuştur. Bu türü sirasiyla $19(\% 46.3)$ adet numunede rastlanan $O$. surinamensis ve 9 (\%22.0) adet örnekte rastlanan $L$. distinguendus türleri izlemiştir (Şekil 3). Çalışma sonunda S.granarius hem yoğunluk oranı bakımından hem de örneklerdeki bulaşıklık durumu bakımından tespiti yapılan türler arasında ilk sırada yer almıştır. Yeni Zelanda'da Chapman vd. [12] tarafindan yapılan çalışmada hububat depolarından alınan örneklerde en sık karşılaşılan tür bu çalışmadan farklı olarak Liposcelis spp. (Psocoptera: Liposcelididae) olmuştur. Benzer şekilde Bağcı vd. [7]'in Ankara ili hububat depolarında yapmış oldukları çalışmada Liposcelis bostrychophila tespit edilen en yoğun tür olmuştur. Ergül vd. [13] tarafindan Doğu ve Güneydoğu Anadolu Bölgelerindeki toplam 11 ilde yapılan çalışmada ve Coşkuncu [8] Bursa'daki un fabrikalarında yaptığı araştırmada, örneklerdeki en yoğun ve bulaşıklık oranı en fazla türün, bu çalıșmayla benzer şekilde, $S$. granarius olduğunu bildirmişlerdir.

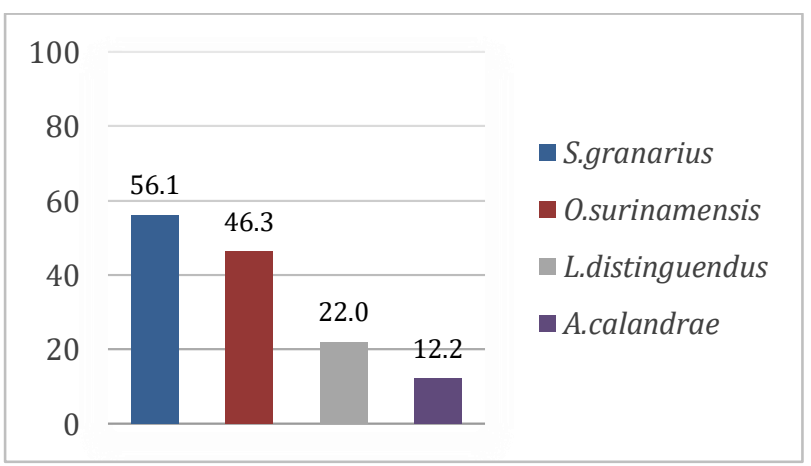


Şekil 3. Kütahya ilinde depolanmıș buğday örneklerinde tespit edilen böcek türleri ile bulaşıklık oranları (\%)

Çalışma süresince alınan 41 örnekten 34'ünün (\%82.9) en az bir böcek türü ile bulașık olduğu, 7 örneğin (\%17.1) ise herhangi bir böcek türü ile bulaşık olmadığı bulunmuştur. Temiz ve bulaşık örnek sayıları ile örneklerin bulaşıklık oranları Tablo 1'de verilmiştir. Böcek bulaşıklığı görülmeyen örnek sayısı Chapman vd. [12] tarafından Yeni Zelanda' da yapılan bir çalışmada \%26.7 olarak bulunmuştur. Bağcl vd. [7] Ankara ili hububat depolarından aldıkları toplam 84 örneğin 45 tanesinde (\%53.6) böcek bulaşıklığına rastlamadıklarını ifade etmişlerdir. Her iki literatürde de örneklerin çoğunlukla ticari silolardan alınmış olması ve örneklenen depolarda kimyasal mücadele yapılması nedeniyle temiz çıkan örnek sayısı daha yüksek bulunmuştur.

Tablo 1 Kütahya ilinde depolanmış buğday örneklerinin böcek bulașıklık oranları

\begin{tabular}{lccc}
\hline İlçe & $\begin{array}{c}\text { Bulaşık } \\
\text { örnek } \\
\text { sayısı }\end{array}$ & $\begin{array}{c}\text { Temiz } \\
\text { örnek } \\
\text { sayısı }\end{array}$ & $\begin{array}{c}\text { Bulaşıklık } \\
\text { oranı } \\
\text { (\%) }\end{array}$ \\
\hline Altıntaş & 8 & 2 & 80.0 \\
Emet & 0 & 3 & 0 \\
Gediz & 5 & 0 & 100 \\
Hisarcık & 8 & 0 & 100 \\
Simav & 5 & 1 & 83.3 \\
Şaphane & 8 & 1 & 88.8 \\
\hline
\end{tabular}

Bir örnekte tespit edilen en fazla farklı tür sayısı 7 olarak bulunmuş ve Çamköy (Şaphane) köyünden alınan örnekte sayılmıștır. Bunu sırasıyla 5 tür ile Hasanlar (Hisarcık) köyü ve 4 türle Göynükören (Gediz), Aşağıdolaylar (Simav), Karamanca (Şaphane) ve Kızılkoltuk (Şaphane) köyleri izlemiştir. Farklı tür sayısı içeren örneklerin toplam alınan 41 örneğe oranı Şekil 4'de verilmiştir.

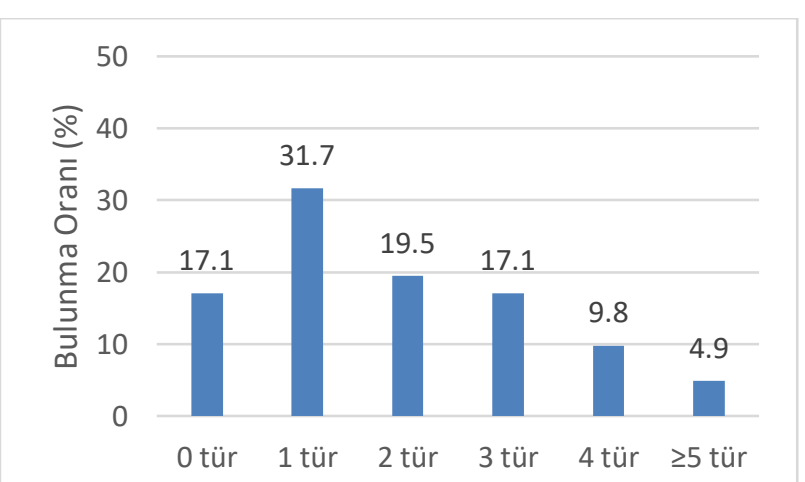

Şekil 4. Kütahya ilinde depolanmış buğday örneklerinde rastlanan farklı sayıdaki türlerin bulunma oranları

Kütahya ilinden 2017 yllında alınan toplam 41 örneğin her birindeki zarar görmüş tane ortalamaları bulunmuş ve bu değerlere tek yönlü varyans analizi uygulanmıştır. Sonuç olarak alınan buğday örneklerinden hesaplanan zarar görmüş tane ortalamaları arasında ilçelere göre farklılıklara rastlanmıştır (Tablo 2). En yüksek ortalama zarar \%10.0 olarak Hisarcık ilçesi Güldüren köyünden alınan örnekte tespit edilmiştir. Bu örnekte tek bir böcek türü tespit edilmiş olmasına rağmen, bu türün S. granarius (primer zararlı) olması ve örnekte 162 adet olarak sayılması ayrıca faydalı türlerin hiçbirine rastlanmaması tanedeki zararın son derece yüksek olmasına neden olmuştur. Hisarcık ilçesi Hasanlar köyünden alınan örnekte $S$. granarius 44 adet tespit edilmiş olmasına rağmen bu örnekteki zarar oranı $\% 2$ olmuştur. Aynı örnekte tespit edilen 33 adet $L$. distinguendus ve 17 adet $A$. calandrae, S. granarius'un bulunma oranının ve dolayısıyla zarar oranının düşük kalmasına neden olmuştur.

Tablo 2. Kütahya ili depolanmış buğday örneklerine ait ortalama zarar oranları $( \pm \mathrm{SH})$

\begin{tabular}{lccc}
\hline \multirow{2}{*}{ Ilçe } & $\begin{array}{l}\text { Örnek } \\
\text { Sayısı }\end{array}$ & \multicolumn{2}{c}{$\begin{array}{c}\text { Zarar Oranı } \\
\text { (Adet/100 tane) }\end{array}$} \\
\cline { 3 - 4 } Altıntas & 10 & $0.12 \pm 0.07 \mathrm{ab}$ & $0.00-0.60$ \\
\hline Emet & 3 & $0.00 \pm 0.00 \mathrm{a}$ & $0.00-0.00$ \\
\hline Gediz & 5 & $1.50 \pm 1.05 \mathrm{ab}$ & $0.0-5.60$ \\
\hline Hisarcık & 8 & $4.28 \pm 1.41 \mathrm{~b}$ & $0.0-10.00$ \\
\hline Simav & 6 & $0.00 \pm 0.00 \mathrm{a}$ & $0.0-0.00$ \\
\hline Saphane & 9 & $1.58 \pm 0.98 \mathrm{ab}$ & $0.0-9.00$ \\
\hline $\begin{array}{l}\text { Toplam } \\
\text { Aynı sütunda aynı harf ile gösterilen ortalamalar } \\
\text { (Tukey p p a }>0.05 \text { ). }\end{array}$ & & & $0.0-10.00$ \\
\hline
\end{tabular}

Işıkber vd. [14] Kahramanmaraş ve Adıyaman illerinde yaptıkları çalışmada örneklerdeki en yüksek zarar oranını \%0.3 olarak tespit etmişlerdir. Yapılan bu çalışmanın 8-12 adet kontrollü ticari silolarda ve yıl boyunca aynı silolarda yapılmış olması, bu zarar oranının düşük kalmasına neden olduğu düşünülmektedir.

\section{Sonuç}

Çalışmanın yapıldığı 2017 yılında Kütahya ilçelerindeki üretici depolarından alınan buğday örneklerinin 34 tanesi en az bir böcek türü ile bulaşık olduğu tespit edilmiştir. Örneklerde, birden fazla canlı primer zararlının bulunması veya bir canlı primer zararlı ile 5 ve üzeri canlı sekonder zararlı olması ya da canlı primer zararlı olmadığı halde 10 'dan fazla canlı sekonder zararlının tespit edilmesiyle, o örneğin alındığı depoya uygun bir bitki koruma ürününün uygulanması gerektiği sonucuna dayanılarak [5], alınan örneklerin 28 tanesinin (toplam örneğin \%68.3) alındığı depoların ilaçlanması gerektiği tespit edilmiştir. Örneklerdeki il geneli zarar ortalaması olan $\% 1.39$, dünya genelinde tahmin edilen \%5'lik böcek zararından daha düşük olmasına rağmen, Hisarcık Güldüren Köyünden alınan örnekte bu oranın \%10, Şaphane Kızllkotuk Köyünden alınan örnekte ise \%9 çıkması oldukça önemli bulunmuştur. Üreticiler tarafından hasat edilen buğdayların depolanması için kullanılan ahşap ya da betonarme yapıların zarar görmüş kısımlarının zamanında ve muntazam bir şekilde onarılması, 
havalandırma pencerelerine zararlı girişini engelleyecek şekilde uygun tellerin takılması gibi kültürel önlemlere dikkat edilmesi gerektiği tespit edilmiştir.

Çalışma sonunda tespit edilen 13 böcek türünden biri olan Anthrenus scrophulariae var. albidus daha önce Türkiye'de değişik habitatlarda ve farklı illerde tespit edilmiş olmasına rağmen Türkiye'deki buğday depolarındaki varlığı ilk kez bu çalışmayla Şaphane Karamanca köyünden alınan örnekte bulunmuştur [15-16].

Yapılan bu çalışma ile Kütahya ilinde bulunan üretici depolarındaki buğdaylarda bulunan böcek türleri, bu türlerin yoğunlukları ve bulaşıklık dereceleri ile doğal düşmanlarının depolardaki durumu ortaya çıkarılmıştır. Araştırmanın bu yönüyle entegre mücadele programları için önemli olacağı düşünülmektedir.

\section{Teşekkür}

Bu çalışma, birinci yazarın doktora tez çalışmasının bir bölümü olup 4771-D1-16 nolu proje ile Süleyman Demirel Üniversitesi BAP Koordinatörlüğü tarafindan desteklenmiştir.

\section{Kaynakça}

[1] Türkiye İstatistik Kurumu, 2019. Bitkisel üretim istatistikleri https://biruni.tuik.gov.tr/medas/?kn=92\&locale $=\operatorname{tr}$ (Erişim Tarihi: 28.11.2019).

[2] Özberk, F., Özberk, İ., Yücel, A., Atll, A., İzol, D. 2017. Khapra Beetle (Trogoderma granarium Everts, 1898) in Durum Wheat (Triticum durum Desf): Impacts on Some Seed Characteristics and Marketing Price. Türkiye Entomoloji Dergisi, 41(2), 207-218.

[3] Donahaye, E.J., Messer, E. 1992. Reduction in Grain Storage Losses of Small-Scale Farmers in Tropical Countries. Research Report RR-91-7, The Allan Shawn Feinstein World Hunger Program, Brown University, USA, 19s.

[4] Emekçi, M., Ferizli, A.G. 2000. Current Status of Stored Products Protection in Turkey. Integrated Protection of Stored Products IOBC Bulletin, 23(10), 39-46.

[5] Rees, D. 2004. Insects of Stored Products. SBS Publishers \& Distiributors PVT. LTD., New Delhi, $181 s$.
[6] Mason, L., McDonough, M. 2012. Biology, Behavior, and Ecology of Stored Grain and Legume Insects. Kansas State University Agricultural Experiment Station and Cooperative Extension Service, 14p, Kansas.

[7] Canadian Grain Commission, 2019. Identify an insect https://www.grainscanada.gc.ca/en/grainquality/manage/identify-an-insect/ (Erişim Tarihi: 28.11.2019).

[8] Bağcl, F., Yılmaz, A., Ertürk, S. 2014. Ankara İli Hububat Depolarında Bulunan Zararlı Böcek Türleri. Bitki Koruma Bülteni, 54(1), 69-78.

[9] Coşkuncu, K. S. 2004. Bursa İli Un Fabrika ve Değirmenlerinde Zararlı Böcek Türleri. Uludağ Üniversitesi Ziraat Fakültesi Dergisi, 18(1), 3344.

[10] Özar, İ., Yücel, A. 1982. Güneydoğu Anadolu Bölgesi'nde Ambarlanan Hububat Ürün Zararlıları Üzerinde Sürvey Çalışmaları. Bitki Koruma Bülteni, 22(2), 89-98.

[11] Öncüer, C. 1991. Türkiye Bitki Zararlısı Böceklerinin Parazit ve Predatör Kataloğu. Ege Üniversitesi Ziraat Fakültesi Basımevi, 314s, İzmir.

[12] Soydanbay Tunçyürek, M. 1976. Türkiye'de Bitki Zararlısı Bazı Böceklerin Doğal Düşman Listesi, Kısım 1. Bitki Koruma Bülteni, 16, 32-46.

[13] Chapman, R.B., Marris, J.V.M., Drummond, J.B. 2016. Survey of Insect Pests of Stored Grain in New Zealand. New Zealand Plant Protection, 69, 285-289.

[14] Ergül, C., Dörtbudak, N., Akülke, A. 1972. Doğu ve Güneydoğu Anadolu Bölgesindeki Hububat ve Mamulleri ile Bakliyat Anbar Zararlılarının Yayılıșı ve Zararı Üzerinde Araştırmalar. Bitki Koruma Bülteni, 12(2),129-143.

[15] Işıkber, A.A., Özdamar, H.Ü., Karcl, A. 2005. Kahramanmaraş ve Adıyaman İlerinde Depolanmıș Buğdaylar Üzerinde Rastlanan Böcek Türleri ve Bulaşma Oranları. Kahramanmaraş Sütçü İmam Üniversitesi, Fen ve Mühendislik Dergisi, 8(1), 107-113.

[16] Tezcan, S., Karsavuran, Y., Pehlivan, E., Hava, J. 2004. Contribution to The Dermestidae (Coleoptera) Fauna of Turkey Alongwith New Records. Türkiye Entomoloji Dergisi, 28(1), 2737. 